\section{Selective reduction of the S-cone component of the \\ electroretinogram in Posner-Schlossman syndrome}

HIDETAKA MAEDA, MAKOTO NAKAMURA, AKIRA NEGI

\begin{abstract}
Purpose The changes in short wavelength sensitive (S-) cone electroretinograms (ERGs) to ganzfeldt flash stimuli were examined in patients with Posner-Schlossman syndrome to study the differences in S-cone action in both the acute attack phase and the remission phase.
\end{abstract}

Methods Ganzfeldt colour flashes under bright white background illumination were used to elicit short wavelength (S-), and mixed long- (L) and middle- (M) wavelength sensitive cone ERGs. Three subjects with unilateral Posner-Schlossman syndrome and 18 age-matched normal controls were compared. To compare the media opacity we obtained the L,M-cone balance, namely, the $\log$ density units of the neutral density filter required to produce the $\mathrm{L}, \mathrm{M}$-cone $\mathrm{b}$-wave elicited with red stimuli which is identical to those with blue stimuli.

Results Selective reduction of the S-cone ERG b-wave in acute attacks of Posner-Schlossman syndrome was found. Two of three cases showed the recovery of the S-cone b-wave with a decrease in the intraocular pressure. With regard to the implicit time, significant delay of the $S$-cone b-wave could not be detected in all subjects.

Conclusion Selective reduction of the S-cone component of the ERG during raised intraocular pressure was found. The S-cone pathway is thought to be more vulnerable to damage than the L,M-cone systems following elevations of intraocular pressure.

Key words Electroretinograms (ERGs), Posner-Schlossman syndrome, S-cone

Glaucomatocyclitic crisis (Posner-Schlossman syndrome) is characterised ${ }^{1,2}$ by unilateral recurrent attacks of cyclitis associated with a markedly elevated intraocular pressure (IOP). The attack and the elevated intraocular pressure usually last from a few hours to several weeks. Most cases have no visual field loss, ${ }^{1}$ retinal dysfunction or optic disc damage due to the self-limiting nature of this disorder. However, it has recently been reported ${ }^{3}$ that occasional glaucomatous visual field damage during the relapses occurs, and surgical treatment is required in cases unresponsive to any medical treatments. On the other hand, previous investigators ${ }^{4-6}$ have reported that shortwavelength sensitivity is reduced in ocular hypertensive eyes. Based on these reports ${ }^{4-7}$ there is some possibility that subclinical retinal dysfunction involving the blue (S-) cone pathway may be present in cases with extremely elevated intraocular pressures. However, little is known about whether or not sensitivity losses for S-cone mechanisms occur in the outer retina in the ocular hypertensive condition. In this study, we measured the Scone response using electroretinograms ${ }^{8}$ (ERGs) to chromatic flashes in patients with Posner-Schlossman syndrome, and examined the differences in S-cone action in both the acute attack phase and the remission phase.

\section{Subjects and methods}

\section{Subjects}

The subjects consisted of three eyes with unilateral Posner-Schlossman syndrome which were followed up at our department and 18 eyes of 18 healthy adult volunteers, from whom informed consent for this study was obtained.

The normal control group (mean age $44.6 \pm 8.5$ years) had no ophthalmological abnormalities except slight ametropia. The group with Posner-Schlossman syndrome (mean age $47.0 \pm 3.0$ years) showed repeated attacks of intraocular pressure elevation to $45-60 \mathrm{mmHg}$ continuing for several days and were diagnosed from the clinical findings.

\section{H. Maeda \\ M. Nakamura \\ A. Negi \\ Department of Ophthalmology Kobe University Kobe, Japan}

H. Maeda Department of Ophthalmology Kobe University School of Medicine

7-5-2 Kusunoki-cho Chuo-ku, Kobe-shi Hyougo-ken 650, Japan

Tel: +81783825111 Fax: +81 783826047 e-mail: hidetaka@med.kobe-u.ac.jp

Received: 16 March 2000 Accepted: 28 July 2000 


\section{Case reports}

Case 1

A 47-year-old man complained of blurred vision in the right eye. This was the second unilateral attack of ocular hypertension. The intraocular pressure was $48 \mathrm{mmHg}$ and the visual acuity was $20 / 20$ in the right eye. Microcystic oedema of the cornea, pigmented keratic precipitates and mild flare of the anterior chamber were noted. The iridocorneal angle was open, with no peripheral anterior synechiae. Neither glaucomatus optic nerve damage nor visual field loss was present in the right eye. Topical eye drops of corticosteroids and $\beta$ antagonists reduced the intraocular pressure to normal levels $(18 \mathrm{mmHg})$.

\section{Case 2}

A 50-year-old man complained of halos around lights, blurred vision and epiphora in the left eye, which had lasted for 1 year. In the left eye, intraocular pressure was $54 \mathrm{mmHg}$ and visual acuity was $18 / 20$. Slit-lamp examination showed slight corneal oedema and fine keratic precipitates. Gonioscopy demonstrated an open iridocorneal angle with no peripheral anterior synechiae. Blurring of vision and halos occurred due to high intraocular pressure. Intraocular pressure decreased to $15 \mathrm{mmHg}$ with topical corticosteroids and $\beta$-antagonists.

\section{Case 3}

A 44-year-old man had blurred vision with photophobia in the left eye. His ocular history revealed several attacks of Posner-Schlossman syndrome. On examination, his best-corrected visual acuity was 18/20 in the left eye; intraocular pressure was $58 \mathrm{mmHg}$ during the attack. Oral carbonic anhydrase inhibitor and topical therapy with corticosteroid, $\beta$-antagonists and adrenaline eye drops could not sufficiently reduce the intraocular pressure to normal levels. Although neither visual field defects nor expansion of the optic disc cupping were recognised, persistence of the elevated intraocular pressure for more than 1 month urged us to perform filtering surgery on this eye, which reduced the intraocular pressure to normal levels $(14 \mathrm{mmHg})$.

In all subjects, the refractive error ${ }^{9}$ ranged from $-5 \mathrm{D}$ to $+3 \mathrm{D}$, and the corrected visual acuity was better than $18 / 20$. To exclude the effects of opacity of the optic media or S-cone sensitivity loss with aging, ${ }^{10}$ the age of the subjects was limited to between 30 and 55 years, and patients with cataract were excluded. Except for mild refractive errors, none of the subjects had other ophthalmic diseases or any systemic disorders. Patients with optic disc characteristics suggestive of glaucomatous damage or other features were excluded. Intraocular pressure was measured with a Goldmann applanation tonometer.

\section{Electroretinographic techniques}

ERGs were recorded both during the acute attack and in the remission phase. The method used to record the ERG was basically identical to that of Gouras ${ }^{8,11}$ and associates. A ganzfeldt stimulator provided full field white background illumination $\left(50 \mathrm{~cd} / \mathrm{m}^{2}\right)$ and flash stimuli. The subject's pupils were fully dilated, generally $8 \mathrm{~mm}$ in diameter, with $0.5 \%$ tropicamide eye drops. The ERGs were recorded from one eye of these subjects using Burian-Allen bipolar contact lens electrodes. At first, the conventional cone ERG was recorded to white stimuli presented at $5 \mathrm{~Hz}$ under white background light $\left(50 \mathrm{~cd} / \mathrm{m}^{2}\right)$. Next, chromatic stimuli ${ }^{8,9,11}$ were obtained with Wratten colour filters (Eastman Kodak, Rochester, NY) $98(450 \mathrm{~nm}), 61(534 \mathrm{~nm}), 21(593 \mathrm{~nm})$ and 29 $(633 \mathrm{~nm})$. (The numbers in parentheses indicate the nominal wavelength of maximum transmission of each filter.) These colour Wratten filter were of gelatinous composition and cut off light of shorter wavelength. The intensities of the flashes were changed by a neutral density filter. Photopic S-cone ERG were elicited with a Kodak Wratten 98 blue filter in front of the ganzfeldt flashbulb which produced white flashes with an intensity of $5.0 \mathrm{~cd} / \mathrm{m}^{2}$. A blue gelatine filter has the characteristics of maximal transmission at 0.550 and half-bandwidth $21.0 \mathrm{~nm}$. The flash duration was $10 \mu \mathrm{s}$, the stimulus frequency was $5 \mathrm{~Hz}$ and 500 responses were averaged under white background light $\left(50 \mathrm{~cd} / \mathrm{m}^{2}\right)$. Responses were averaged with the use of a Neuropack 4 averager (Nihon Kohden, Tokyo, Japan). The frequency range was 5-1000 Hz for the recording of the S-cone ERG. We routinely obtained responses using the maximum flash intensity available at $450 \mathrm{~nm}$ and then dimmed the other stimuli with neutral density filters to produce an approximately equal L,M-cone b-wave, because all longer-wavelength stimuli had more effective energy for the L- and M-cones. To compare the media opacity (lens yellowing or corneal opacity), we obtained the L,M-cone balance, ${ }^{8}$ namely the log density units of the neutral density filter required to produce the L,M-cone b-wave elicited with red stimuli which were identical to those with blue stimuli. The media opacity reduces the short wavelength transmissivity, L,M-cone b-wave amplitude as well as the S-cone amplitude. Thus, L,M-cone balance increases with lens yellowing because long wavelength transmissivity is not greatly affected. We examined the cone ERG in both the acute attack phase and the remission phase.

\section{Aqueous humour sample paracentesis}

We aspirated aqueous humour $(20 \mu \mathrm{l})$ using a 27 -gauge needle from the three patients with clinically diagnosed Posner-Schlossman syndrome during acute attacks of the syndrome, extracted DNA, and conducted polymerase chain reaction amplification.

The analysis of statistical data was carried out using the Mann-Whitney $U$-test. The confidence interval and the probability level were set at $99 \%$ and $1 \%$ for statistical significance. 
Table 1. Clinical background of the two groups

\begin{tabular}{lccc}
\hline & \multicolumn{3}{c}{ Posner-Schlossman } \\
& Control & syndrome & $p$ value \\
\hline Age (years) & $44.6 \pm 8.5$ & $53.3 \pm 6.0$ & 0.42 \\
Refraction (D) & $-2.2 \pm 1.1$ & $-3.0 \pm 1.4$ & 0.28 \\
IOP (mmHg) & $16.1 \pm 2.2$ & $53.3 \pm 5.0$ & $<0.01^{* *}$ \\
Visual acuity & 1.0 over & 0.9 & \\
\hline
\end{tabular}

** $p<0.01$ compared with controls (Mann-Whitney $U$-test).

\section{Results}

The clinical backgrounds of the normal control group and the patients with Posner-Schlossman syndrome are shown in Table 1. No significant difference was observed in any parameter except the intraocular pressure between the two groups (Mann-Whitney $U$-test).

The white flash cone ERG b-wave amplitude and implicit time in all subjects are shown in Table 2. The cone ERG b-wave amplitude and implicit time were similar in the two groups. No statistically significant reduction in white flash cone ERG b-wave in either amplitude or implicit time were found in Posner-Schlossman syndrome compared with normal control eyes. Fig. 1 illustrates the corneal ERG response to short and long wavelength flash intensities in the presence of a white adapting field. In normal subjects (A, $\mathrm{B})$, the S-cone ERG elicited by short wavelength $(450 \mathrm{~nm})$ stimuli appeared as a separate b-wave riding on an early mixed L- and M-cone b-wave. We measured the S-cone b-wave response from its initial appearance, after the peak of the L,M-cone b-wave, to its own peak for the 450 $\mathrm{nm}$ stimulus. The mean for S-cone b-wave amplitude in 18 normal subjects aged from 30 to 51 years was $1.26 \mu \mathrm{V}$ and implicit time was approximately $45 \mathrm{~ms}$. To middle and long wavelength stimuli, only the $\mathrm{L}, \mathrm{M}$-cone $\mathrm{b}$-waves were generated (implicit time to peak $25 \mathrm{~ms}$ ). Table 2 summarises amplitudes and implicit times of the S-cone b-wave to $450 \mathrm{~nm}$ stimuli and those of the L,M-cone bwave to $633 \mathrm{~nm}$ stimuli in normal subjects and patients with Posner-Schlossman syndrome. S-cone ERG amplitude ranged from 0.86 to $1.84 \mu \mathrm{V}$ in normal controls. During the acute crisis of Posner-Schlossman syndrome, all 3 cases showed selective reduction of Scone b-wave amplitude. For the L,M-cone b-wave, there was no significant difference in amplitude or in implicit times between the two groups. Cases 1 and 2 showed recovery of the S-cone b-wave with the decrease in intraocular pressure (Fig. 2). However, recovery of the $\mathrm{S}$-cone $\mathrm{b}$-wave could not be detected in the complicated case 3 even in the remission phase.

There was no significant difference in the L,M-cone balance, i.e. the ratio of long $(633 \mathrm{~nm})$ to short $(450 \mathrm{~nm})$ wavelength filtering required to produce identical L,Mcone b-waves. This finding implies that differences in the opacity of dioptric media - lens yellowing or corneal oedema due to intraocular elevation - were probably negligible in this study.

From samples of aqueous humour aspiration, no amplification signal for the herpes simplex virus or varicella zoster virus DNA probe sequence was detected in these three cases (Cases 1-3).

\section{Discussion}

Posner-Schlossman syndrome typically presents as an acute unilateral pressure elevation associated with mild inflammation. ${ }^{1,2}$ Intraocular pressure during an attack often reaches the range of $40-70 \mathrm{mmHg}$; some complicated cases show visual field defects despite topical treatment. However, no previous study has reported retinal dysfunction in Posner-Schlossman syndrome in association with excessive intraocular pressure elevation. Several psychophysical studies have demonstrated the vulnerability of the S-cone pathways in ocular hypertension ${ }^{6}$ and glaucoma. ${ }^{5,12}$ In particular,

Drance et al. ${ }^{7}$ have reported that diffuse sensitivity loss of the blue (S-) cone pathway was found in ocular hypertensive eyes with blue-on-yellow perimetry. The Scone pathway has been monitored using chromatic VEP techniques in normal subjects ${ }^{13}$ and in a number of conditions including diabetes and central serous chorioretinopathy. ${ }^{14}$ Selective reduction of S-cone sensitivity in vivo has not been verified in Posner-Schlossman syndrome by using any objective methods. In addition, little is known about the actual Scone responses in patients with Posner-Schlossman syndrome from electrophysiological experiments. In this study, we measured S-cone function objectively, in vivo, in patients with Posner-Schlossman syndrome, using a modified electroretinographic technique. ${ }^{8}$

From our results, selective reduction of S-cone ERG components can be recognised in cases of elevated intraocular pressure associated with Posner-Schlossman syndrome. Moreover, cases 1 and 2 showed recovery of

Table 2. White flash cone, $S$-cone and $L, M$-cone electroretinogram (ERG) b-wave

\begin{tabular}{|c|c|c|c|c|c|c|c|}
\hline & \multicolumn{2}{|c|}{$\begin{array}{l}\text { Cone ERG b-wave } \\
\text { (white flash) }\end{array}$} & \multicolumn{2}{|c|}{$\begin{array}{l}\text { S-cone ERG b-wave } \\
\qquad(450 \mathrm{~nm})\end{array}$} & \multicolumn{2}{|c|}{$\begin{array}{l}\text { L,M-cone ERG b-wave } \\
(633 \mathrm{~nm})\end{array}$} & \multirow{2}{*}{$\begin{array}{c}\begin{array}{c}\mathrm{L}, \mathrm{M} \text {-cone } \\
\text { balance }\end{array} \\
\text { (LDU) }\end{array}$} \\
\hline & $\begin{array}{l}\text { Amplitude } \\
(\mu \mathrm{V})\end{array}$ & (ms) IT & $\begin{array}{l}\text { Amplitude } \\
(\mu \mathrm{V})\end{array}$ & (ms) IT & $\begin{array}{l}\text { Amplitude } \\
(\mu \mathrm{V})\end{array}$ & (ms) IT & \\
\hline Controls (18 eyes) & $83.1(21.4)$ & $33.1(2.53)$ & $1.46(0.52)$ & $45.5(2.65)$ & $2.85(1.34)$ & $27.4(1.73)$ & $0.52(0.22)$ \\
\hline $\begin{array}{l}\text { Posner-Schlossman } \\
\text { syndrome ( } 3 \text { eyes) }\end{array}$ & $82.4(16.6)$ & $32.6(1.79)$ & $0.77(0.27)^{* *}$ & $46.8(2.25)$ & $2.57(0.74)$ & $27.7(0.73)$ & $0.48(0.10)$ \\
\hline
\end{tabular}

Values are the mean \pm SD.

IT, implicit time.

${ }^{* *} p<0.01$ compared with controls (Mann-Whitney $U$-test). 


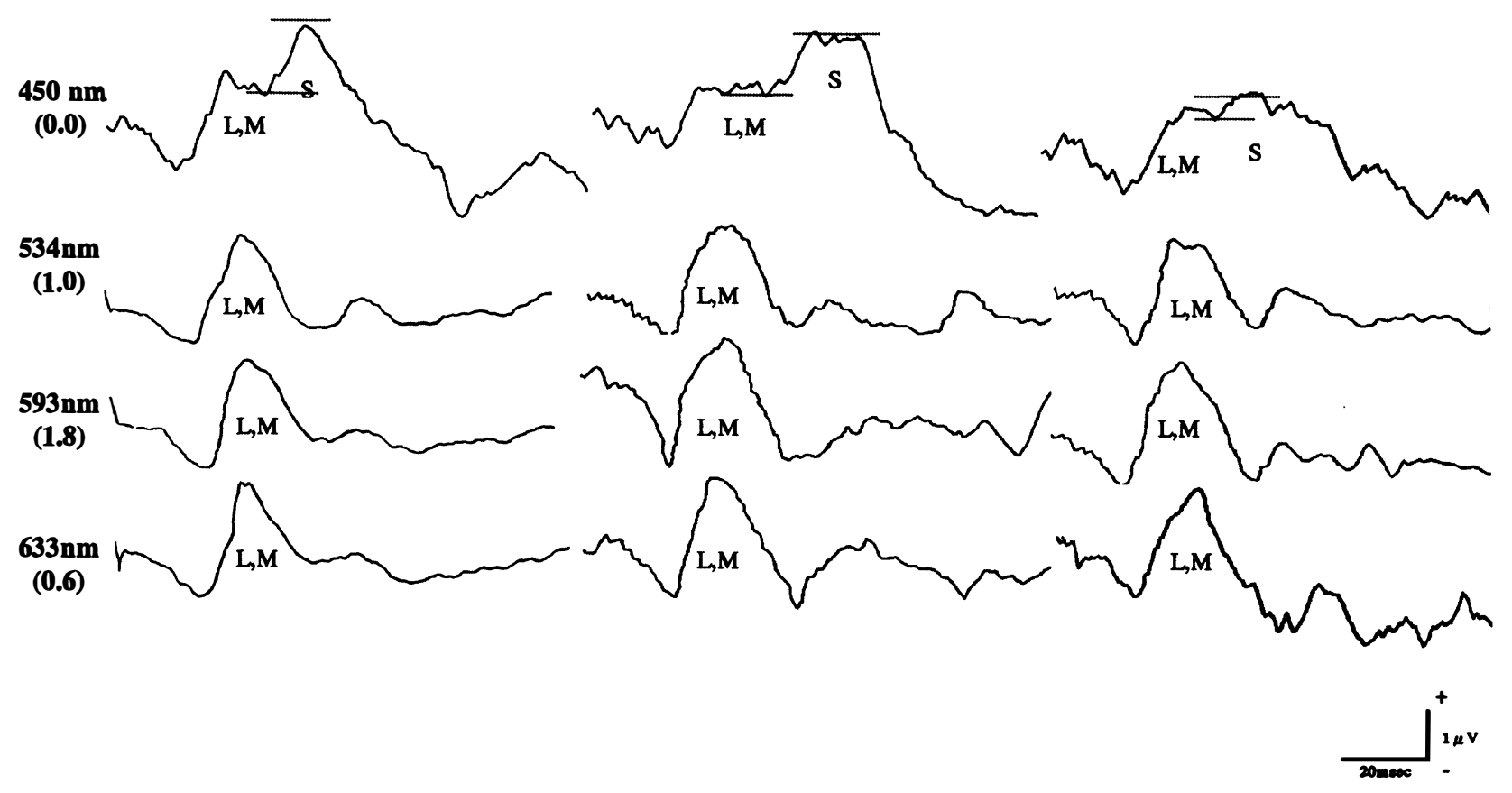

Fig. 1. Cone electroretinograms (ERGs) showing the response to different chromatic stimuli from a 46-year-old (A) and a 51-year-old (B) normal subject and a 49-year-old Posner-Schlossman patient (C). The numbers on the left signify the nominal wavelength of maximum transmission of each filter in nanometres. Numbers in parentheses indicate the neutral density filter used to adjust the energies of the flashes to produce approximately equal early (L,M-cone) b-waves. The broken lines indicate the $S$-cone b-waves that were measured. $S$ signifies $S$-cone b-wave, and $L, M$ signifies $L, M$-cone b-wave.

S-cone b-wave amplitude when the intraocular pressure returned to normal values. However, case 3 showed Scone reduction in spite of a reduction in the intraocular pressure. Pressure elevation persisted for about 1 month and necessitated surgical treatment. The irreversible reduction of S-cone b-wave amplitude in this case suggests that subclinical retinal dysfunction including

\section{Acute phase}

Case 1

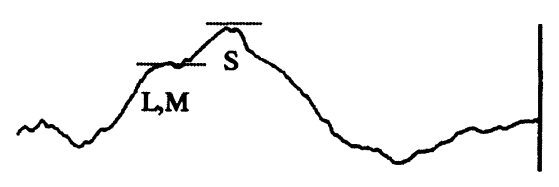

(IOP=60 $\mathrm{mmHg}$ )

Case 2

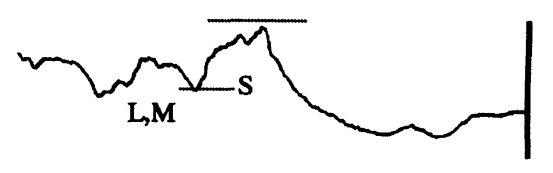

(IOP=54mmHg)

Case 3

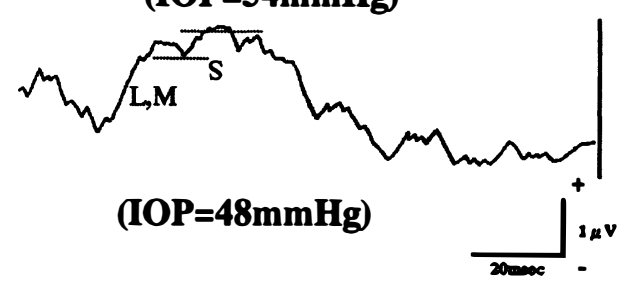

the S-cone pathways might have been caused despite the absence of visual field loss. L- and M-cone responses were not affected even in Posner-Schlossman syndrome.

It has been reported that the S-cone pathway is more vulnerable to hypoxia ${ }^{15,16}$ than the $\mathrm{L}$ - and M-cone systems, so we speculate that hypoxia of chromatic cells in photoreceptor level could be caused by breakdown of

\section{Remission phase}
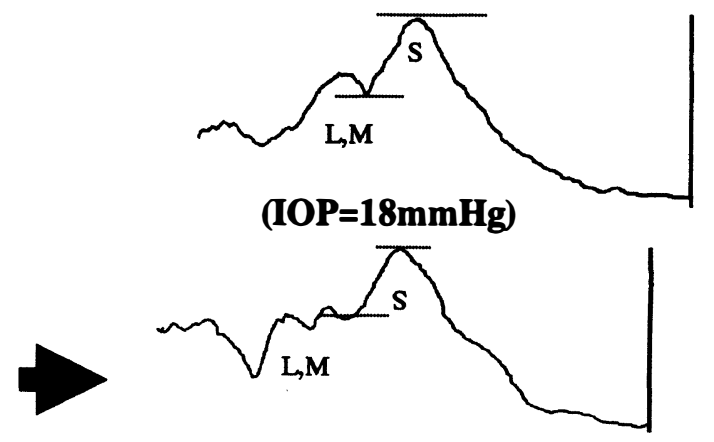

(IOP=15mmHg)

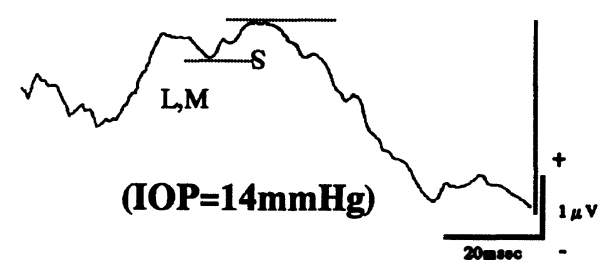

Fig. 2. S-cone ERGs from our three cases of Posner-Schlossman syndrome. Cases 1 and 2 showed a significant reduction in the S-cone b-wave amplitude in the acute phase, and a recovery of the $S$-cone b-wave with the decrease in intraocular pressure. 
retinal vein autoregulation system and a decrease in choroidal blood flow volume with an increase in intraocular pressure. Another possibility is that functional depression of selective S-cone chromatic signal in cell-to-cell interaction between neuron and glia ${ }^{17,18}$ in the retina may be caused when extreme elevation of intraocular pressure has occurred. These results may imply that significant diffuse losses of ganglion cells making up the S-cone sensitive visual pathways may occur in patients with acute glaucoma crisis. Furthermore, several investigators ${ }^{19,20}$ have reported that the short wavelength sensitivity (S) cones represent a minority ${ }^{21}$ of the cone photoreceptors in the human retina. The retinal neural pathway of the S-cone responses also differs from those of $\mathrm{L}, \mathrm{M}$-cones. S-cones pool their signals in large receptive fields. ${ }^{19}$ In the S-cone pathway, there is a preponderance of S-cone 'on' units at the ganglion cell level. ${ }^{21}$ Selective reduction of S-cone ERGs may be partially caused by these minority of blue cones.

It is unlikely that the reduction in S-cone b-wave amplitude would have been caused by the degradation of corneal transparency ${ }^{22}$ due to high intraocular pressure, since the $\mathrm{L}, \mathrm{M}$-cone balance was almost identical in the acute phase of Posner-Schlossman syndrome compared with normal controls.

The mechanisms responsible for Posner-Schlossman syndrome are still obscure. Yamamoto et al. ${ }^{23}$ reported that herpes simplex virus may play a role in the origin of Posner-Schlossman syndrome. However, it is unclear whether the herpes viruses are aetiological agents in Posner-Schlossman syndrome. Indeed, in this study, all three specimens from aqueous humour paracentesis were negative for amplified genomic fragments of herpes simplex virus and varicella zoster virus. It is also unlikely that herpes simplex virus causes S-cone reduction in ERG and led to retinal damage in this study.

From our reports, the S-cone pathway was thought to be more vulnerable ${ }^{8,20,24}$ than the L,M-cone systems when a striking elevation of intraocular pressure has occurred, which is thought to suppress the S-cone signal pathway in the sensory retina. ${ }^{25}$ It will be interesting to follow Posner-Schlossman syndrome prospectively in patients whose S-cone ERGs are reduced below the normal range. Also, it is still not clear whether S-cone reduction can be a predictor of early glaucomatous change. Further studies will be needed to assess the fluctuation of S-cone responses associated with elevations in intraocular pressure.

\section{References}

1. Posner A, Schlossman A. Syndrome of unilateral recurrent attacks of glaucoma with cyclitic symptoms. Arch Ophthalmol 1948;39:517-35.

2. Sokolic P. Developmental factor in the etiopathogenesis of glaucomatocyclitic crisis. Ophthalmologica 1970;161:446-50.

3. Kass MA, Becker B, Kolker AE. Glaucomatocyclitic crisis and primary open-angle glaucoma. Am J Ophthalmol 1973;75:668-73.
4. Joost F, Leo AMS de Jong, Thomas JTP van den Berg, Erick LG. Functional characteristics of blue-on-yellow perimetric thresholds in glaucoma. Invest Ophthalmol Vis Sci 1995;36:1665-74.

5. de Jong LAMS, Snepvangers CEJ, van den Berg TJTP, Langerhorst CT. Blue-yellow perimetry in the detection of early glaucomatous damage. Doc Ophthalmol 1990;45:303-14

6. Heron G, Adams AJ, Husted R. Central visual fields for short wavelength sensitive pathways in glaucoma and ocular hypertension. Invest Ophthalmol Vis Sci 1988;29:64-72.

7. Drance SM, Lakowski R, Shulzer M, Douglas GR. Acquired color vision changes in glaucoma: use of 100-Hue test and Pickford anomaloscope as predictors of glaucomatous field change. Arch Ophthalmol 1981;99:829-31.

8. Gouras P, Mackey CJ. Electroretinographic responses of short-wave sensitive cones. Invest Ophthalmol Vis Sci 1990;31:1203-9.

9. Yamamoto S, Nitta K, Kamiyama M. Cone electroretinogram to chromatic stimuli in myopic eyes. Vision Res 1997;37:2157-9.

10. Johnson CA, Adams AJ, Twelker JD, Qugg JM. Age-related changes in the central visual field for shortwavelengthsensitive pathways. J Opt Soc Am A 1988;5:131-9.

11. Gouras P, Mackey CJ, Yamamoto S. The human S-cone electroretinogram and its variation among subjects with and without L- and M-cone function. Invest Ophthalmol Vis Sci 1993;34:2437-42.

12. Yokoyama M. Blue sensation in eye disease. Jpn J Clin Ophthalmol 1973;33:111-25.

13. Robson AG, Kulikowski JJ. Objective specification of tritanopic confusion lines using visual evoked potentials. Vision Res 1998;38:3499-503.

14. Rabin J, Adams AJ. Cortical potentials evoked by short wavelength patterned light. Optom Vis Sci 1992;69:522-31.

15. Yamamoto S, Kamiyama M, Nitta K, Yamada T, Hayasaka S. Selective reduction of the $S$ cone electroretinogram in diabetes. Br J Ophthalmol 1996;80:973-5.

16. Smith VC, Ernest JT, Pokorny J. Effect of hypoxia on FM 100-hue test performance. Mod Probl Ophthalmol 1976;17:248-56.

17. Greenstein VC, Hood DC, Ritch R, Steinberger D, Carr RE. $\mathrm{S}$ (blue) cone pathway vulnerability in retinitis pigmentosa, diabetes and glaucoma. Invest Ophthalmol Vis Sci 1989;30:1732-7.

18. Tanihara H, Hangai M, Sawaguchi S, Abe H, Kageyama F, Shirasawa E, Honda Y. Up-regulation of glial fibrillary acidic protein in the retina of primate eyes with experimental glaucoma. Arch Ophthalmol 1997;115:752-6.

19. Kolb H, Lipetz LE. The anatomical basis for color vision in the vertebrate retina. In: Gouras P, editor. The perception of color. London: Macmillan Press, 1991:128-45.

20. Calkins DJ, Tsukamoto Y, Sterling P. Microcircuitry and mosaic of a blue-yellow ganglion cells in the primate retina. J Neurosci 1998;18:3373-85.

21. De Monasterio FM. Asymmetry of on and off-pathways of blue-sensitive cones of the retina of macaques. Brain Res 1979;166:39-48.

22. Sawusch M, Pokorny J, Smith VC. Clinical electroretinography for short wavelength sensitive cones. Invest Ophthalmol Vis Sci 1987;28:966-75.

23. Yamamoto S, Pavan-Langston D, Tada R, Yamamoto R, Kinoshita S, Nishida K, Shimomura Y, Tano Y. Possible role of herpes simplex virus in the origin of Posner-Schlossman syndrome. Am J Ophthalmol 1995;119:796-8.

24. Norren DV, Padmos P. Human and macaque blue cones studied with electroretinography. Vision Res 1973;13:1241-54.

25. Yokoyama K, Yoshida T, Uji K. Spectral responses in the human electroretinogram and their clinical significance. Jpn J Ophthalmol 1973;17:113-24. 